\title{
DIREITO ADMINISTRATIVO E JUSTIÇA SOCIAL
}

\author{
ADMINISTRATIVE LAW AND SOCIAL JUSTICE
}

\section{Cristina Vázquez}

Professora Titular de Direito Administrativo da Universidade da República (Uruguay). Doutora em Direito e Ciências Sociais pela Universidade da República (Uruguay), Mestre em Ciências da legislação e Governança Política da Universidade de Pisa (Italia).

\section{Resumo}

O presente estudo realiza o exame do conceito de "justiça social" no âmbito das organizações internacionais e revela sua importância para o Direito Administrativo. Em seguida, é analisado o conceito de direitos sociais e sua exigibilidade no contexto do sistema de proteção social no Uruguai. Por fim, este artigo conclui que o direito à educação tratase de um "direito habilitante" para a obtenção de uma verdadeira justiça social.

Palavras-chave: Direito Administrativo; justiça social; direitos sociais; direito à educação.

\begin{abstract}
This study examines the concept of "social justice" in international organizations and reveals its importance for administrative law. Then, the concept of social rights and their enforceability in the context of the social protection system in Uruguay is analyzed. Finally, this article concludes that the right to education is a "enabling right" to obtain true social justice.
\end{abstract}

Key-words: Administrative Law; Social Justice; Social rights; rigth to education.

1 Tradução do original em espanhol por Rodrigo Leite Ferreira Cabral. 


\section{INTRODUÇÃO}

Neste trabalho começaremos pelo exame do conceito de "justiça social" e sua relevância para o Direito Administrativo.

Na sequência, analisaremos a noção de direitos sociais, revisando a questão da sua exigibilidade, para depois examinar o sistema de proteção social no Uruguai.

Concluiremos com algumas reflexões finais, destacando a importância do direito à educação, como "direito habilitante" para a obtenção de uma verdadeira justiça social.

\section{JUSTIÇA SOCIAL. SUA RELEVÂNCIA NO DIREITO ADMINISTRATIVO}

A expressão "justiça social" é utilizada no âmbito de organizações tão relevantes e diversas como são a Organização Internacional do Trabalho (OIT), a Igreja Católica e a Organização das Nações Unidas (ONU), dentre outras.

No preâmbulo da Constituição da Organização Internacional do Trabalho (OIT), de 1919, se consigna que "a paz universal e permanente somente pode basear-se na justiça social". E, com maior extensão, na Declaração relativa aos fins e objetivos da OIT (Declaração da Filadélfia de 1944), se afirma que

\footnotetext{
"(a) todos os seres humanos, qualquer que seja a sua raça, a sua crença ou o seu sexo, têm o direito de efetuar o seu progresso material e o seu desenvolvimento espiritual em liberdade e com dignidade, com segurança económica e com oportunidades iguais;

b) a realização das condições que permitem atingir este resultado deve constituir o objetivo central de qualquer política nacional e internacional;

c) todos os programas de ação e medidas tomadas no plano nacional e internacional, nomeadamente no domínio económico e financeiro, devem ser apreciados deste ponto de vista e aceites apenas na medida em que pareçam favorecer, e não prejudicar, o cumprimento deste objetivo fundamental; ..."
}

Por sua vez, a expressão aparece nas Cartas Encíclicas de Pio XI, Quadragésimo Anno de 15 de maio de 1931 e Divini Redemptoris de 19 de março de 1937.

Na primeira, nos números 58 e 110, se expressa:

58. A cada qual, por conseguinte, deve dar-se o seu, na distribuição dos bens, sendo necessário que a repartição dos bens criados se revogue e se ajuste às normas do bem comum ou da justiça social, pois qualquer pessoa sensata vê quão gravíssimo transtorno acarreta a si esta enorme diferença atual entre uns poucos carregados de fabulosas riquezas e a incontável multitude de necessitados."

"110: As instituições públicas devem adequar toda a sociedade humana às 
exigências do bem comum, ou seja, à norma da justiça social, com o qual esse importantíssimo setor da vida social, que é a economia não poderá fazer menos do que se enquadrar dentro de uma ordem reta e sã."

Também se expressa:

A economia social estará solidamente constituída e alcançar[a seus fins somente quando a todos e a cada um sejam providos todos os bens que as riquezas e subsídios naturais, a técnica e a constituição social da economia possam produzir.

Esses bens devem ser suficientemente abundantes para satisfazer as necessidades e as honestas comodidades e elevar aos homens aquela condição de vida mais feliz, que, administrada prudentemente, não somente não impede a virtude, como também a favorece em grande número.

Na Divini Redemptoris, a expressão “justiça social” aparece nos números 31, 52 e 53.

No número 31 assinala que a ordem econômica e social devem configurar-se de acordo com a justiça social, com a "unidade harmônica e coerente de todas as associações, para que possam tender, todas elas, ao bem comum do Estado", sendo essa harmoniosa coordenação de todas as forças sociais a "missão genuína e peculiar do poder político".

No 52, acrescenta:

Porque é um fato certo que, ao lado da justiça comutativa, deve-se afirmar a existência da justiça social, que impõe deveres específicos aos que não se furtar nem aos patrões, nem aos operários. E é precisamente próprio da justiça social exigir dos indivíduos todo o necessário para o bem comum. Agora, assim como um organismo vivo não se atende suficientemente à totalidade do organismo, se a cada parte e cada membro não é dado o que é necessário para exercitar suas próprias funções, da mesma forma não se pode atender suficientemente à constituição equilibrada do organismo social e ao bem de toda a sociedade se não se dá a cada parte e a cada membro, é dizer, aos homens, dotados de dignidade de pessoa, todos os meios que necessitem para cumprir sua particular função social. Portanto, o cumprimento dos deveres próprios da justiça social terá como efeito uma intensa atividade que, nascida no seio da vida econômica, amadurecerá na tranquilidade da ordem e demonstrará a saúde integral do Estado, da mesma forma que a saúde do corpo humano se reconhece externamente na atividade inalterada e, ao mesmo tempo, plena e frutífera de todo o organismo.

No caso da ONU, em 2007, sua Assembleia Geral proclamou o dia 20 de fevereiro de cada ano, como o Dia Mundial da Justiça Social. Na justificativa, sustentou que "a justiça social é um princípio fundamental para a convivência pacífica e próspera", constituindo "o núcleo" de "sua missão global para promover o desenvolvimento e a dignidade humana".

As Nações Unidas assinalam que as atividades que se sejam desenvolvidas em virtude desse Dia Mundial da Justiça Social, devem ser orientadas a "erradicar a pobreza e promover o pleno emprego e o trabalho decente, a igualdade entre os sexos e o acesso

Revista de Direitos Fundamentais \& Democracia, Curitiba, v. 24, n. 3, p. 138-155, set./dez., de 2019. 
ao bem-estar social e à justiça social para todos".

Em definitiva, é possível verificar que essa expressão, cujas raízes normalmente são vinculadas à noção de justiça distributiva, do pensamento aristotélico tomista, vai se adequando até o ponto de apanhar os conteúdos mencionados, que se apresentam fortemente relacionados aos denominados direitos econômicos, sociais e culturais e com a demanda pela atuação do Estado, na busca de sua proteção e satisfação.

Nesse cenário, o Direito Administrativo é necessariamente convocado, como Direito público regulador da atividade administrativa, no que diz respeito à organização e funcionamento das pessoas públicas.

\section{O CONSTITUCIONALISMO SOCIAL E A CONSTITUIÇÃO URUGUAIA.}

Desde a Ciência Política, Daniel Chasquetti identifica três pontos de inflexão no processo constitucional uruguaio", caracterizado por "um núcleo duro de preceitos e disposições", que permaneceu inalterado como "édito perpétuo", no dizer de Justino Jiménez de Aréchaga, incluindo "a filosofia e organização republicana e democrática do país, a igualdade dos cidadãos perante a Lei, a liberdade de crença e a separação da igreja do Estado, os direitos individuais e sociais, a divisão de poderes, os organismos controladores e de justiça social e, particularmente, a prevalência de um pluripartidarismo co-participativo".

A partir da perspectiva de Chasquetti, "o desenho e redesenho das instituições de governo tem sido um processo pautado por três grandes reformas aprovadas em 1918, 1934 e 1966". ${ }^{3}$

Entre os que denominada "os três grandes pontos de inflexão no processo constitucional uruguaio", destaca o segundo, a reforma constitucional aprovada em 1934. E, sobre a mesma, em relação ao tema objeto deste trabalho, expressa: "Paradoxalmente, a Convenção Nacional Constituinte, eleita em circunstâncias muito especiais (resultado do autogolpe do presidente Gabriel Terra), elaborou um texto constitucional que definiria o formato final das principais instituições da democracia uruguaia. Ademais, aquela Constituição reconheceu direitos econômicos, sociais e culturais, e assumiu uma atitude ativa do Estado sobre o tema do ensino, trabalho,

\footnotetext{
2 CHASQUETTI, Daniel, Tres puntos de inflexión en el proceso constitucional uruguayo, en https://ladiaria.com.uy/articulo/2016/6/tres-puntos-de-inflexion-en-el-proceso-constitucional-uruguayo/ ${ }^{3}$ As demais reformas, de 1942, 1952 e 1996, foram, em sua opinião, emendas que obedeciam à atuação de grupos interessados em obter vantagens políticas específicas.
} 
moradia, direito de greve, propriedade intelectual, família, maternidade, etc. Esse salto superlativo de Direitos foi influenciado pela aparição de uma série de textos constitucionais de grande envergadura, como a Constituição de Querétaro (México), de 1917, e a Constituição de Weimar (Alemanha), de 1919."

\section{ASPECTOS CONCEITUAIS E ENQUADRAMENTO JURÍDICO GERAL DOS DIREITOS SOCIAIS}

É possível afirmar que a questão da resposta administrativa aos direitos sociais tem a ver com um dos temas de maior presença na opinião pública e no debate político de nossos dias, o de que os direitos humanos devem se fazer presentes na base de todas as políticas pública, entendendo essas como os "cursos de ação desenvolvidos pelo governo, em relação com um objetivo determinado, que contribuem a criar ou transformar as condições em que se desenvolvem as atividades dos indivíduos e dos diversos grupos sociais" 4 .

Se tem destacado que essas políticas públicas devem ser globais em um triplo sentido, de acabar os diferentes Poderes do Estado, projetar-se para além de um período de governo e contar com a participação da sociedade civil, em seu conjunto ${ }^{5}$.

É habitual ver os direitos humanos classificados por categorias, empregando-se diversos critérios. O mais conhecido deles é o que os enquadra por gerações: a primeira, a das liberdades fundamentais e dos direitos civis e políticos; a segunda, a dos direitos econômicos, sociais e culturais; e a terceira, dos Direitos dos Povos e de Solidariedade ${ }^{6}$, que otimizam o desenvolvimento de uma pessoa em um ambiente apropriado ${ }^{7}$.

Observa Uiarte ${ }^{8}$, que esse agrupamento "tem um sentido pedagógico e facilitador, sem que se possa ser considerada uma divisão científica", referindo-se sobretudo às distintas etapas histórico-sociológicas, em que foram sendo reconhecidos

\footnotetext{
${ }^{4}$ Veja-se: LAHERA PARADA, Eugenio, Introducción a las políticas públicas, Breviarios Fondo de Cultura Económica, Chile, 2002.

5 GARRETÓN, Roberto, Las Naciones Unidas y los Derechos Humanos en el actual panorama mundial, ESADE, FAC. de Derecho, Barcelona, España, 1997, Ed. Marzal.

${ }^{6}$ AGUILAR CUEVAS, Magdalena, Las tres generaciones de los derechos humanos, Biblioteca Jurídica Virtual, http://www.juridicas.unam.mx/publica/librev/rev/derhum/cont/30/pr/pr20.pdf

Como exemplo, normalmente são mencionados os direitos de autodeterminação, independência econômica e política, identidade e cultura nacional, paz, convivência pacífica, uso de avanços na ciência e tecnologia e meio ambiente, dentre outros.

8 URIARTE, Daoiz, Curso de derechos humanos y sus garantías, Tomo I, Mont. Ed. FCU, 2013, p. 24.
} 
esses direitos.

Além do já desenvolvido sobre essa classificação, é interessante a enfática e interpeladora observação realizada sobre o tema pelo Juiz Texier ${ }^{9}$ :

Falar sobre os direitos de primeira, segunda e terceira geração me parece uma total aberração. É óbvio que os direitos econômicos, sociais e culturais nascem ao mesmo tempo que os direitos civis e políticos; é óbvio que são direitos humanos. Eu gostaria que essa terminologia sobre gerações - artifício de juristas que adoram criar categorias - se apagasse definitivamente do vocabulário. .

Entre os direitos chamados de segunda geração normalmente incluem-se o direito à seguridade social, ao trabalho em condições equitativas e satisfatórias, à sindicalização, a um nível de vida adequado que assegure ao indivíduo, assim como a sua família, saúde física e mental, alimentação, vestuário, moradia, assistência médica, educação e cuidados e assistência em circunstâncias especiais, tais como na maternidade, infância ou incapacidade.

Uriarte destaca como características de ditos direitos:

a) sua finalidade de igualdade material entre os seres humano, assegurando condições de existência digna;

b) a exigência de participação ativa do Estado na sua promoção, desenvolvimento e garantia;

c) sua condição de direitos coletivos e, ao mesmo tempo, individuais;

d) sua operatividade, mesmo quando sua aplicabilidade sofre condicionamentos próprios dos recursos públicos e da sociedade; e

e) sua progressividade ao estar em um contínuo desenvolvimento, na medida em que o desenvolvimento econômico e social permita ampliar de forma permanente seu nível de proteção.

Atria $^{10}$, por sua vez, observa que, na tradição liberal, os direitos se fundam naquilo que ele denomina de "auto-interesse", de modo que a recepção dos direitos sociais supõe alargar dito "auto-interesse", "como uma espécie de seguro que cada agente faz para prevenir-se da possibilidade de acabar sem cobertura e necessitado". E cita a Steven Holmes, que assinala que, nessa perspectiva, basta o asseguramento de

\footnotetext{
${ }^{9}$ TEXIER, Phillip (magistrado e juiz da Câmara de Direito do Trabalho, do Tribunal de Cassação de Paris. Membro do Comitê de Direitos Econômicos, Sociais e Culturais das Nações Unidas), Exigibilidad de los derechos económicos, sociales y culturales en los sistemas universales de protección de los derechos humanos, in Construyendo una agenda para la justiciabilidad de los derechos sociales, impresso por Gossestra Intl. S.A., San José, Costa Rica, 2004.

${ }^{10}$ ATRIA, Fernando, ¿Existen derechos sociales?, Discusiones, № 4 (2004),p. 31.Biblioteca Virtual Miguel de Cervantes, Alicante, http://www.cervantesvirtual.com/obra/existen-derechos-sociales-0/
}

Revista de Direitos Fundamentais \& Democracia, Curitiba, v. 24, n. 3, p. 138-155, set./dez., de 2019. 
um mínimo que permita dar ao cidadão um nível apenas que seja apenas superior à vida "solitária, pobre, desagradável, bruta e breve de que fala Hobbes", de modo que os demais possam exigir respeito à autoridade.

Na perspectiva de um Estado com preocupação social, por outro lado, os direitos sociais são uma manifestação de uma forma superior de comunidade, "em que cada um de seus membros tem um interesse no bem-estar do outro... do berço até o túmulo".

Encontramos o reconhecimento dos direitos econômicos, sociais e culturais, também conhecidos como direito "da igualdade", tanto nos ordenamentos jurídicos nacionais, como nas normas internacionais.

No plano internacional vale mencionar, dentre outros, o Pacto Internacional de Direitos Econômicos, Sociais e Culturais.

No preâmbulo do referido Pacto Internacional são recordados os princípios enunciados na Carta das Nações Unidas, de acordo com os quais a liberdade, a justiça e a paz no mundo têm por base o reconhecimento da dignidade inerente a todos os membros da família humana e de seus direitos iguais e inalienáveis. Se declara, também, que "de acordo com a Declaração Universal dos Direitos Humanos, o ideal do ser humano livre, livre do medo e da miséria, não pode ser realizado, a menos que sejam criadas condições que permitam a cada pessoa usufruir de seus direitos econômicos, sociais e culturais, bem como seus direitos civis e políticos."

O preâmbulo não esquece, por sua vez, da outra face dos direitos, a dos deveres de todo indivíduo para com os outros indivíduos e a comunidade a que pertence.

Sobre o direito ao trabalho, o Pacto Internacional de Direitos Econômicos, Sociais e Culturais declara o direito de toda pessoa a "ter a oportunidade de ganhar a vida mediante um trabalho livremente escolhido e aceito" e a uma remuneração que proporcione, no mínimo, "um salario equitativo e igual por trabalho de igual valor, sem distinções de nenhuma espécie; em particular, deve assegurar-se às mulheres condições de trabalho que não sejam inferiores às dos homem, com salario igual por trabalho igual", condições de existência digna para o trabalhador e sua família, seguridade e higiene no trabalho, igualdade de oportunidade de promoção, direito ao descanso, à sindicalização e à greve, de acordo com as leis de cada pais (artigos 6 e 7).

No Pacto são reconhecidos, especialmente, o direito à seguridade social (artigo 9), à mais ampla proteção e assistência possíveis à família, com ênfase na proteção das mães antes e depois do parto, e das crianças e adolescentes (artigo 10); a um nível de vida adequado para o indivíduo e sua família, incluindo alimentação, vestuário e moradia, 
com a melhora contínua das condições de existência e, em particular, o direito a ser protegido contra a fome (artigo 11); o direito ao gozo do mais alto nível possível de saúde física e mental (artigo 12); à educação, que deve orientar-se em direção ao pleno desenvolvimento da personalidade humana e do sentido de sua dignidade, preceituando o ensino primário obrigatório e gratuito, a generalização e o acesso ao ensino secundário e superior, com a implantação progressiva de sua gratuidade (artigo 13); assim como os direitos de participar na vida cultura e gozar dos benefícios do progresso científico (artigo 15).

Por sua parte, no Sistema Interamericano dos Direitos Humanos, o Protocolo Adicional à Convenção Americana sobre os Direitos Humanos em Matéria de Direitos Econômicos, Sociais e Culturais (Protocolo de San Salvador) reconhece, além dos mencionados, o direito a um meio ambiente sadio (artigo 12), e o direito a proteção dos idosos (artigo 17) e aos deficientes (artigo 18).

Já no Direito interno, os direitos econômicos, sociais e culturais encontram-se reconhecidos na Constituição da República. $\mathrm{O}$ artigo $7^{\circ}$ declara o direito dos habitantes a serem protegidos no gozo de seus direitos, dentre os quais inclui o direito ao trabalho, de modo que ninguém possa ser privado de eles, senão de acordo com as leis que estabeleçam razões de interesse geral.

De modo mais específico, a Carta reconhece o direito à proteção da família (artigo 40), incluindo os que têm prole numerosa o direito e receber auxílios compensatórios, quando assim necessitem, e o direito da infância e juventude a serem protegidos contra o abandono corporal, intelectual ou moral de seus pais ou tutores, assim como contra a exploração e o abuso (artigo 41); o direito à proteção da maternidade, qualquer que seja a condição ou estado da mulher, e a sua assistência em caso de desamparo (artigo 42).

Consagra o dever de legislar em todas as questões relativas à saúde e higiene públicas, procurando o aperfeiçoamento físico, moral e social de todos os habitantes do país, acompanhado do direito de receber gratuitamente os meios de prevenção e assistência aos indigentes ou aos carentes de recursos suficientes (artigo 44), o direito de gozar de moradia condigna, com obrigação de legislar com o objetivo de assegurar moradia higiênica e econômica, proporcionando e estimulando o investimento de capitais privados para esse fim (artigo 45), a obrigação do Estado de disponibilizar abrigo aos indigentes ou carentes de recursos suficientes que, por sua inferioridade física o mental de caráter crônico, sejam incapacitados para o trabalho (artigo 46), e declara o interesse 
geral na proteção do meio ambiente e o direito de acesso à água potável e ao saneamento (artigo 47).

Sobre o trabalho, inclui disposicoes relativas à sua protecao legal, com obrigação para a coletividade de procurar, com preferência aos cidadãos, a possibilidade de tirar seu sustento mediante o desenvolvimento de uma atividade econômica (artigo 53), o direito do trabalhador à justa remuneração, a limitação da jornada, o descanso semanal e a higiene física e moral, com obrigação de regulamentare e limitar o trabalho das mulheres e dos menores de dezoito anos (artigo 54), a obrigação de regulamentação legal da distribuição imparcial e equitativa do trabalho (artigo 55), e a de toda empresa, cujas características determinem a permanência de pessoal no respectivo estabelecimento, de fornecer alimentação e alojamento adequados (artigo 56), e a promoção legal da organização de sindicados gremiais, reconhecendo franquias e estabelecendo normas para reconhecer-lhes a personalidade jurídica e o direito de greve, como direito gremial (artigo 57).

Em matéria de previsão social, preceitua a organização das aposentadorias gerais e seguros sociais, de modo a garantir a todos os trabalhadores, patronos, empregados e operários, aposentadorias adequadas e subsídios para todos os casos de acidentes, doenças, invalidez, desemprego forçado, e a suas famílias, em caso de morte, à pensão correspondente. Consagra, também, o direito à pensão por velhice para aquele que chegue ao limite da idade produtiva, despois de um longo período de permanência no pais e para o que necessite de recursos para pagar suas necessidades vitais, com a preceptiva de que a correção das aposentadorias e pensões não poderá ser inferior ao valor do Índice Médio de Salários, efetuando, nessas mesmas oportunidades em que se estabeleçam ajustes ou aumento das remunerações dos funcionários da administração em geral (artigo 67).

O artigo 69 estabelece que as instituições de ensino privado e as culturais da mesma natureza estarão insentos de impostos nacionais e municipais, como subvenção por seus serviços e o artigo 70 dispõe como obrigatórios o ensino primário e médio, agrário ou industrial, acrescentando que o Estado dará preponderância ao desenvolvimento da pesquisa científica e do ensino técnico e que a lei proverá o necessário para a efetividade dessas disposições.

No artigo 71, declara-se de utilidade social a gratuidade do ensino oficial primário, médio, superior, industrial e artístico e de educação física, a criação de bolsas para aperfeiçoamento e especialização cultural, científico e operária, e o 
estabelecimento de bibliotecas populares.

Finalmente, o artigo 72 declara que a enumeração de direitos, deveres e garantias que a Constituição realiza não exclui outros inerentes à personalidade humana ou que derivem da forma republicana de governo.

\title{
5. A QUESTÃO DA EXIGIBILIDADE DOS DIREITOS SOCIAIS
}

Muito se tem discutido sobre a exigibilidade desses direitos e, inclusive, se tem debatido sobre a sua real condição como tais, a partir de uma perspectiva que afirma que não existe direito subjetivo, sem dever correlativo e sem ação que permita reclamar o seu exercício.

Nada obstante, por outro lado, se tem assinalado que "nos direitos humanos, a bilateralidade tradicional da relação sinalagmática se altera"11 e, nesse mesmo sentido, que "porque eu tenha o direito a navegar não posso pretender que qualquer pessoa se converta em um sujeito passivo obrigado (...) Para conceder aos direitos humanos a natureza de direitos subjetivos, descartamos que seja essencial a disponibilidade de acesso desse titular a uma via coativa, no aparato jurisdicional do Estado". ${ }^{12}$

No artigo $2^{\circ}$ do Pacto Internacional de Direitos Econômicos, Sociais e Culturais, se dispõe:

\begin{abstract}
1. Cada Estado Parte do presente Pacto compromete-se a adotar medidas, tanto por esforço próprio como pela assistência e cooperação internacionais, principalmente nos planos econômico e técnico, até o máximo de seus recursos disponíveis, que visem a assegurar, progressivamente, por todos os meios apropriados, o pleno exercício dos direitos reconhecidos no presente Pacto, incluindo, em particular, a adoção de medidas legislativas.

2. Os Estados Partes do presente Pacto comprometem-se a garantir que os direitos nele enunciados e exercerão em discriminação alguma por motivo de raça, cor, sexo, língua, religião, opinião política ou de outra natureza, origem nacional ou social, situação econômica, nascimento ou qualquer outra situação. 3. Os países em desenvolvimento, levando devidamente em consideração os direitos humanos e a situação econômica nacional, poderão determinar em que garantirão os direitos econômicos reconhecidos no presente Pacto àqueles que não sejam seus nacionais.
\end{abstract}

Como assinala Saura Estapà, ${ }^{13}$ os direitos sociais, da mesma forma que os direitos civis e políticos, contém tanto elementos prestacionais, quanto elementos de

\footnotetext{
11 URIARTE, Daoiz, Curso de derechos humanos y sus garantías, ob. cit., p. 19.

12 LARRALDE, Jorge, citado por Uriarte, ob. cit. p. 20.

13 SAURA ESTAPÀ, Jaume, La exigibilidad jurídica de los derechos humanos: especial referencia a los derechos económicos, sociales y culturales (DESC), El tiempo de los derechos, Facultad de Derecho, Universidad de Barcelona, Instituto de Derechos Humanos de Catalunya, 2001.
} 
abstenção. Eles têm um conteúdo essencial, que pode ser exigível sem desenvolvimento normativo algum, e um conteúdo necessário para dar de si sua melhor potencialidade, que requere esse desenvolvimento.

O autor destaca, seguindo Martínez de Pisón, que "a exigibilidade dos direitos sociais remete à possibilidade de postular judicialmente o cumprimento das obrigações derivadas". Sem embargo, acrescenta, exigibilidade e judiciabilidade não são sinônimos, já que "o recurso judicial é só uma, ainda que talvez a mais potente, das vias para exigirse os direitos diante dos poderes públicos".

Nessa linha de análise e tomando o enfoque de Abramovich y Courtis, ${ }^{14}$ Saura Estapà distingue dois tipos de exigibilidade, a direta que se refere ao reconhecimento dos direitos na ordem normativa (garantias normativas) e a possibilidade de postular perante os tribunais (garantias jurisdicionais); a indireta, que permite a defesa através da invocação de princípios gerais, como a igualdade, a não discriminação ou o direito à tutela judicial efetiva. Seguindo Pisarello, ${ }^{15}$ alude ao caso de "justiciabilidade por conexão", que permite a tutela dos direitos sociais em virtude de sua relação com outros direitos "fundamentais", como na Constituição espanhola o direito de audiência (artigo 105), o direito a receber informação (artigo 20), o direito de participar em assuntos públicos (artigo 23), o direito de não ser discriminado (artigo 14).

A exigibilidade do direito, explica Saura Estapà, tem a ver com a concreção de seu conteúdo essencial, a identificação de seus titulares e do responsável por torná-lo efetivo, assim como a existência de vias formais de acesso dos primeiros aos segundos.

Ditas vias de acesso podem ser tanto jurisdicionais como administrativas ou outras.

Deve-se ter em conta, por sua vez, em relação ao tema da exigibilidade dos direitos, que, enquanto os textos normativos declarativos de direitos civis e políticos estabelecem normalmente obrigações imediatas e de resultado, os que reconhecem direitos sociais, como o Pacto Internacional de Direitos Econômicos, Sociais e Culturais, por exemplo, normalmente incluem obrigações que foram denominadas "de comportamento", o que, como é natural, confere alcance distinto à resposta administrativa ou jurisdicional respectiva.

\footnotetext{
${ }^{14}$ ABRAMOVICH, Víctor y COURTIS, Christian, Los derechos sociales como derechos exigibles, Trotta, Madrid, 2002.

${ }^{15}$ PISARELLO, Gerardo, La justiciabilidad de los derechos sociales en el sistema constitucional español, en Los derechos sociales como derechos justiciables: potencialidades y límites, Editorial Bomarzo, Albacete, 2010.
} 
Assim, por exemplo, no Pacto de Direitos Civis e Políticos, os Estados se obrigam "a respeitar e garantir a todos os indivíduos que se achem em seu território e que estejam sujeitos a sua jurisdição os direitos reconhecidos (...) sem discriminação alguma" (artigo 2.1.), enquanto que no Pacto de Direitos Econômicos, Sociais e Culturais, como já adiantado, o compromisso do Estado é o de "adotar medidas (...) até o máximo de seus recursos disponíveis, que visem a assegurar, progressivamente, por todos os meios apropriados, o pleno exercício dos direitos" (artigo 2.1).

\section{O SISTEMA DE PROTEÇÃO SOCIAL NO URUGUAI.}

A partir do antes exposto, a seguir se procurará realizar uma brevíssima análise das políticas públicas, institucionalidade e marco normativo através dos quais se pretendeu, nos últimos anos, dar uma resposta administrativa aos direitos sociais no Uruguai.

No documento intitulado El sistema de protección en Uruguay"16 se menciona como princípios ou pilares do que dito documento denomina "a reforma social inclusiva", os seguintes:

1) De cada qual, de acordo com suas rendas (seja através de impostos, como no caso da educação, ou de contribuições de seguridade social, no caso da saúde) e a cada qual, segundo suas necessidades (associadas a idade, sexo, localização no território, tamanho do lar, etc.). ${ }^{17}$

2) Universalidade do acesso, enquanto desenho das políticas não pressupõe ações focalizadas para dar resposta a um problema concreto, mas sim ações que convirjam a situações de todas as pessoas, sem prejuízo da definição de prioridades (assim, por exemplo, no caso da reforma do setor de saúde, com crianças e adolescentes). Nesse sentido, se assinala que a focalização e ações afirmativas são ferramentas "para gerar trajetórias rumo aos sistemas universais.

3) Condução do Estado.

\footnotetext{
${ }^{16}$ OLESKER, Daniel (Ministro do Desenvolvimento Social do Uruguai que realizou esse sistema no período de governo entre 2010 e 2015), El sistema de protección en Uruguay, Seminario Internacional Políticas Públicas para la Igualdad: Hacia Sistemas de Protección Social Universal, Torre Ejecutiva de la Presidencia de la República, Montevideo, Uruguay 4 y 5 de diciembre de 2013, enhttp://www.mides.gub.uy/innovaportal/file/24880/1/olesker_el_sistema_de_proteccion_social_en_urug uay.pdf

17 Essa é a expressão da ideia de solidariedade manifestada comunitariamente, segundo Fernando Atria, op. cit.
} 
4) Participação social, de maneira que as pessoas organizadas (em sindicatos, organizações de usuários ou mulheres, dentre outras organizações), participem das políticas sociais em suas três fases: desenho, execução e tomada de decisões

5) Aumento orçamentário para complementar os recursos de desenvolvimento da política social.

O documento se refere a uma "trajetória que vá da inclusão à igualdade, passando pela integração social" e acrescenta que "a matriz de proteção social se compõe, também, de um conjunto de políticas de caráter transversal, vinculadas a atributos das pessoas, tais como o gênero, a idade, a origem étnico-racial, as incapacidades ou a orientação sexual, e à dimensão territorial. Elas compreendem um conjunto de ações afirmativas para respaldar o exercício de direitos".

Na continuação, se constrói uma matriz de proteção social no Uruguai, com os seguintes componentes:

1) No setor da saúde, o Sistema Nacional Integrado de Saúde (SNIS), ${ }^{18}$ com responsabilidades assinaladas fundamentalmente ao Ministério da Saúde Pública (MSP), ${ }^{19}$ a Administração dos Serviços de Saúde do Estado (ASSE), ${ }^{20}$ o Hospital de Clínicas, ${ }^{21}$ Saúde Militar e Saúde Policial, ${ }^{22}$ ademais das atuações políticas focalizadas, como o Fortalecimento da Rede de Atenção de Primeiro Nível (RAP), Saúde rural, Conselhos de Saúde e Saúde de Pessoas Privadas de Liberdade.

2) No setor da educação, o Sistema Nacional de Educação Pública, ${ }^{23}$ com responsabilidades assinaladas fundamentalmente ao Ministério de Educação e Cultura (MEC), a Administração Nacional de Educação Pública (ANEP), ${ }^{24}$ a

\footnotetext{
18 Pelo artigo 264 da Lei $n^{\circ}$ 17.930, de 19 de dezembro de 2005, o Ministério da Saúde Pública compromete-se a implementar um Sistema Nacional de Saúde Integrado, com o objetivo de estabelecer atendimento integral a todos os residentes do país, garantindo sua cobertura equitativa e universal. A norma acrescenta que "esse sistema será articulado com base na complementação público-privada e terá como estratégia global a atenção primária à saúde, priorizando o primeiro nível de ações de assistência, promoção, prevenção e reabilitação. O sistema complementará os serviços públicos e privados, a fim de obter atendimento de qualidade abrangente e adequado para todos os habitantes. "

${ }^{19}$ Sua Lei Orgânica é 9.202, de 12 de janeiro de 1934.

20 Serviço descentralizado criado pela Lei no 18.161, de 29 de julho de 2007.

21 Hospital Universitário dependente da Universidade da República que, além das tarefas de ensino, realiza tarefas de assistência, extensão e pesquisa.

${ }^{22}$ Respectivamente, no âmbito dos Ministérios da Defesa Nacional e Interna.

${ }^{23}$ Ver Lei Nacional de Educação n 18.437, de 12 de dezembro de 2008.

${ }^{24}$ Entidade Autônoma criada pela Lei no 15.739, de 28 de março de 1985.
} 
Universidade da República ${ }^{25}$ e a Universidade Tecnológica, ${ }^{26}$ assim como atuações em políticas focalizadas, como Programa Professores Comunitários (PMC), Programa Salas Comunitárias (PAC), Formação Professional Básica (FPB) e Compromisso Educativo.

3) No setor de moradia, o Sistema Público de Moradia, com responsabilidades assinaladas fundamentalmente ao Ministério de Moradia, Ordenamento Territorial e Meio Ambiente (MVOTMA), ${ }^{27}$ al Banco Hipotecário do Uruguai (BHU), ${ }^{28}$ a Agencia Nacional de Moradia (ANV) ${ }^{29}$ e o Movimento de Erradicação de Moradia Insalubre Rural (MEVIR), ${ }^{30}$ com atuações em políticas focalizadas, como Subsídios à quota, Programa de Autoconstrução de Moradia Rural, Subsídios de Aluguel e Programa de Integração de Assentamentos Irregulares (PIAI).

4) No setor de trabalho, com as leis de negociação coletiva $(N \circ 18.566$, de 11 de setembro de 2009), Emprego Juvenil $(N \circ 19.133$, de 20 de setembro de 2013) e cúmplices de afrodescendência (№ 19.122 , de 21 de agosto de 2013), com requisitos de carga dos Ministérios de Trabalho e Segurança Social (MTSS) e Desenvolvimento Social (MIDES), e ações em políticas focalizadas, como se verá no parágrafo seguinte designado a este Ministério.

5) No setor que o documento denomina de Proteção, se destacam o Sistema de Cuidados com o Centro de Atenção Integral à Infância e Família (CAIF), regulação de Lares de Longa Estadia, assistentes pessoais para deficientes, formação de assistentes, e nova lei de licenciamento parental (№ 19.161, de $1^{\circ}$ de novembro de 2013), com responsabilidade fundamental dos Ministérios do Desenvolvimento Social (MIDES), Trabalho e Segurança Social (MTSS) e Saúde Pública (MSP), Instituto da Criança e Adolescente do Uruguai $\left(\right.$ INAU) ${ }^{31}$, Banco de Previdência Social (BPS ${ }^{32}$ e Associações Familiares (AFAM), como ações em políticas focadas, como Ações Múltiplas em Pessoas Privadas de

\footnotetext{
${ }^{25}$ Lei Orgânica n 12.549, de 16 de outubro de 1958.

${ }^{26}$ Entidade Autônoma criada pela Lei no 19.043, de 28 de dezembro de 2012.

${ }^{27}$ Lei $n^{\circ} 16.112$, de 30 de maio de 1990.

${ }^{28}$ Entidade Autônoma, cuja Carta Orgânica é a Lei $n^{\circ}$ 5.343, de 22 de outubro de 1915, instituição financeira especializada em crédito hipotecário, para facilitar o acesso à moradia.

29 Serviço descentralizado, criado pela Lei oㅜ 18.125, de 27 de abril de 2007, com o objetivo de promover e facilitar o acesso à habitação.

${ }^{30}$ Pessoa pública não estatal (artigos 473 e segs., Lei n 13.640, de 26 de dezembro de 1967).

${ }^{31}$ Serviço Descentralizado, criado pela Lei no 15.977, de 14 de setembro de 1988.

32 Entidade Autônoma Necessária, de criação constitucional (artigo 195).
} 
Liberdade ou Ações Múltiplas em Criança e Adolescência e Assistência à Velhice.

\section{RESPUESTA DESDE EL MINISTERIO DE DESARROLLO SOCIAL}

Pela Lei no 17.866, de 21 de março de 2005, foi criado o Ministério do Desenvolvimento Social, assinalando suas atribuições a de assessoramento ao Poder Executivo, proposta, formulação, execução, supervisão, coordenação, programação, acompanhamento e avaliação das políticas nacionais, estratégias e planos nas áreas de juventude, mulher e família, adultos maiores, incapazes e desenvolvimento social em geral (artigo 9o).

É também responsável pela coordenação de ações, planos e programas intersetoriais, implementados pelo Poder Executivo para garantir o exercício pleno dos direitos sociais à alimentação, educação, saúde, moradia, desfrute de um meio ambiente são, trabalho, segurança social e não discriminação.

Ele deve projetar, organizar e operar um sistema de informação social com indicadores relevantes sobre grupos populacionais em situações de vulnerabilidade, o que permite um foco adequado no conjunto de políticas e programas sociais nacionais e um sistema único de identificação, seleção e registro de núcleos familiares ou indivíduos autorizados a acessar programas sociais.

É também responsável por implementar, executar e coordenar programas de atenção à emergência social, cobrindo as necessidades básicas daqueles em situação de miséria e pobreza extrema e fornecendo a eles informações e assessoramento sobre os programas disponíveis.

Por sua vez, o Ministério tem expressamente assinalados poderes de regulamentação, promoção, acompanhamento e monitoramento das atividades das entidades estatais que atuam no campo da juventude, mulher, idosos, deficientes, afrodescendentes e diversidade sexual, conforme apropriado, bem como o poder-dever de supervisão de qualquer instituição privada com a qual execute programas sociais sob a modalidade de convênio, quanto ao seu efetivo cumprimento. $\mathrm{O}$ artigo 10 da lei the confere o poder de punir administrativamente ${ }^{33}$.

Ele também é responsável por estabelecer áreas de coordenação e aconselhamento com a sociedade civil envolvida em seus objetivos.

33 Vide: artigo 221 da Lei no 19.670, de 15 de outubro de 2018. 


\section{REFLEXIONES FINALES}

Muitas vezes, quando se alude a justiça social, se enfatiza sua manifestação no âmbito dos direitos econômicos.

Para concluir essa apresentação, sem embargo, gostaria de trazer para o primeiro plano a importância do direito à educação, como direito humano fundamental, felizmente reconhecido atualmente pelos ordenamentos jurídicos nacionais e também por diversos instrumentos internacionais.

O direito à educação é princípio reitor da Agenda Mundial Educação 2030 e Objetivo de Desenvolvimento Sustentável 4 (ODS 4) da comunidade internacional.

Sua enorme transcendência radica na sua qualidade de "direito habilitante", isto é, direito que abre caminho a outros direitos.

Nesse sentido, já na Declaração Universal dos Direitos Humanos, adotada pela Assembleia das Nações Unidas, em dezembro de 1948, se assinala que: "A educação tem por objeto o pleno desenvolvimento da personalidade humana e o fortalecimento do respeito aos direitos humanos e às liberdades fundamentais".

Isso, lamentavelmente, não impede que milhões de pessoas ainda continuem privadas de seu gozo, seja por fatores econômicos, sociais ou culturais.

Dentre outras iniquidades, a falta de acesso à educação manteve, durante milênios, a mulher afastada da possibilidade de contribuir com seu pensamento e ação ao desenvolvimento humano.

Vale destacar que, em tão difícil contexto, uma mulher do século XVII, que conseguiu superar as restrições de seu tempo e converter-se em uma precursora do pensamento moderno - a filósofa e escritora inglesa Mary Wollstonecraft - sentenciava em relação ao tema que nos ocupa: "É justiça social e não caridade o que o mundo precisa".

De nossa parte, acreditamos justo abonar no sentido de um harmônico equilíbrio entre justiça social e caridade, virtude essa que se incentiva desde o primeiro dos Mandamentos, ordenamento amar o próximo como a si mesmo.

\section{REFERÊNCIAS}

ABRAMOVICH, Víctor y COURTIS, Christian. Los derechos sociales como derechos exigibles, Trotta, Madrid, 2002. 
AGUILAR CUEVAS, Magdalena. Las tres generaciones de los derechos humanos, Biblioteca Jurídica Virtual, http://www.juridicas.unam.mx/publica/librev/rev/derhum/cont/30/pr/pr20.pdf

ATRIA, Fernando. ¿Existen derechos sociales?, Discusiones, No 4 (2004),p. 31. Biblioteca Virtual de Cervantes, Alicante, http://www.cervantesvirtual.com/obra/existen-derechos-sociales-0/

CHASQUETTI, Daniel. Tres puntos de inflexión en el proceso constitucional uruguayo, en https://ladiaria.com.uy/articulo/2016/6/tres-puntos-de-inflexion-en-elproceso-constitucional-uruguayo/

GARRETÓN, Roberto. Las Naciones Unidas y los Derechos Humanos en el actual panorama mundial, ESADE, FAC. de Derecho, Barcelona, España, 1997, Ed. Marzal.

OLESKER, Daniel. El sistema de protección en Uruguay, Seminario Internacional Políticas Públicas para la Igualdad: Hacia Sistemas de Protección Social Universal, Torre Ejecutiva de la Presidencia de la República, Montevideo, Uruguay 4 y 5 de diciembre de 2013, enhttp://www.mides.gub.uy/innovaportal/file/24880/1/olesker_el_sistema_de_proteccion _social_en_uruguay.pdf

PISARELLO, Gerardo. La justiciabilidad de los derechos sociales en el sistema constitucional español, en Los derechos sociales como derechos justiciables: potencialidades y límites, Editorial Bomarzo, Albacete, 2010.

SAURA ESTAPÀ, Jaume. La exigibilidad jurídica de los derechos humanos: especial referencia a los derechos económicos, sociales y culturales (DESC), El tiempo de los derechos, Facultad de Derecho, Universidad de Barcelona, Instituto de Derechos Humanos de Catalunya, 2001.

TEXIER, Phillip. Exigibilidad de los derechos económicos, sociales y culturales en los sistemas universales de protección de los derechos humanos, en 
Construyendo una agenda para la justiciabilidad de los derechos sociales, impreso por Gossestra Intl. S.A., San José, Costa Rica, 2004.

URIARTE, Daoiz, Curso de derechos humanos y sus garantías, Tomo I, Mont. Ed. FCU, 2013, p. 24.

VÉASE LAHERA PARADA, Eugenio, Introducción a las políticas públicas, Breviarios Fondo de Cultura Económica, Chile, 2002.

Recebido em 14/10/2019 Aprovado em 30/10/2019 Received in 14/10/2019 Approved in 30/10/2019 